\title{
Perfil de resistência e ou sensibilidade antibacteriana de enterobactérias coletadas de ovos de p. expansa
}

A ordem Testudines conhecidos atualmente como quelônios, compreendem as tartarugas, jabutis e cágados). Esses animais são ovíparos e depositam seus ovos em diferentes ambientes. Diante do exposto objetivou-se identificar e traçar o perfil de resistência e ou sensibilidade antimicrobiana de enterobactérias coletadas de ovos P. expansa. Os microrganismos foram coletados de 10 ninhos na praia alta município de Lagoa da Confusão/TO. Foram identificadas 1.200 colônias de enterobactérias, distribuídas entre os gêneros Enterobacter ssp. Citrobacter spp. Shigella spp. Hafnia ssp. Klebsiella spp. Proteus spp. Salmonella spp. e a espécie E. coli. sendo Enterobacter ssp. (33,33\%), Citrobacter spp. (20,83\%), Shigella spp. (12,5\%), E. coli (20,83\%) Hafnia ssp. (8,33\%), Klebsiella spp. (2,08\%), Proteus spp. $(1,67 \%)$, Salmonella spp. $(0,42 \%)$. Quanto ao perfil de resistência e ou sensibilidade obtidos foi detectado multirresistência aos antimicrobianos em todos os microrganismos, alguns com resistência a mais de 03 dos antibióticos testados. Os resultados obtidos neste estudo ressaltam a importância de se conhecer o perfil de enterobactérias isoladas de ovos de P. expansa, tendo em vista que tais bactérias são encontradas como integrantes da microbiota residente e transitória de $\mathrm{P}$. expansa e da areia das praias. E. coli, Shigella spp., Hafnia spp., e Citrobacter spp. foram os microrganismos que apresentaram resistência ao maior número de antimicrobianos utilizados. Enterobacter spp, E. coli e Citrobacter spp. foram as enterobactérias encontradas em maior número de ovos, podendo estar relacionadas com a microbiota da areia da praia, contaminando os ovos por via horizontal.

Palavras-chave: Antibiograma; Colonização de ovos; Salmonelose.

\section{Profile of resistance and or antibacterial sensitivity of enterobacteria collected from eggs of $p$. expansa}

\begin{abstract}
The Order Testudines known today as turtles, comprise turtles, tortoises and turtles). These animals are oviparous and lay their eggs in different environments. Given the above, the objective was to identify and trace the profile of resistance and or antimicrobial sensitivity of enterobacteria collected from eggs from $P$. expansa. The microorganisms were collected from 10 nests on the high beach of Lagoa da Confusão/TO. 1,200 colonies of enterobacteria were identified, distributed among the Enterobacter ssp. Citrobacter spp. Shigella spp. Hafnia ssp. Klebsiella spp. Proteus spp. Salmonella spp. and E. coli. Enterobacter ssp. (33.33\%), Citrobacter spp. (20.83\%), Shigella spp. (12.5\%), E. coli (20.83\%) Hafnia ssp. (8.33\%), Klebsiella spp. (2.08\%), Proteus spp. (1.67\%), Salmonella spp. (0.42\%). Regarding the resistance and / or sensitivity profile obtained, multidrug resistance to antimicrobials was detected in all microorganisms, some with resistance to more than 03 of the tested antibiotics. The results obtained in this study emphasize the importance of knowing the profile of enterobacteria isolated from $\mathrm{P}$. expansa eggs, considering that these bacteria are found as members of the resident and transitory microbiota of $\mathrm{P}$. expansa and the sand on the beaches. E. coli, Shigella spp., Hafnia spp., And Citrobacter spp. were the microorganisms that showed resistance to the largest number of antimicrobials used. Enterobacter spp, E. coli and Citrobacter spp. were the enterobacteria found in the largest number of eggs, which may be related to the microbiota of the beach sand, contaminating contaminating the eggs horizontally.
\end{abstract}

Keywords: Antiogram; Egg colonization; Salmonellosis.

Topic: Microbiologia Agrícola e Ambiental

Reviewed anonymously in the process of blind peer.

Rosildo Mendes Evangelista Sobrinho (iD) Universidade Federal do Tocantins, Brasil http://lattes.cnpq.br/2107480220875125 http://orcid.org/0000-0001-7859-4484 rosildo.sobrinho@gmail.com

\section{Adriana Malvásio (D)}

Universidade Federal do Tocantins, Brasil http://lattes.cnpq.br/9694032726460437 http://orcid.org/0000-0001-8020-3307 malvasio@mail.uft.edu.br

Aparecido Osdimir Bertolin (10)

Universidade Federal do Tocantins, Brasil http://lattes.cnpq.br/8017919306165978 http://orcid.org/0000-0002-8343-4060

drbertolin@gmail.com
Received: 02/08/2020

Approved: 19/09/2020

\section{Referencing this:}

EVANGELISTA SOBRINHO, R. M.; MALVÁSIO, A.; BERTOLIN, A. O.. Perfil de resistência e ou sensibilidade antibacteriana de enterobactérias coletadas de ovos de p. expansa. Revista Ibero Americana de Ciências Ambientais, v.11, n.5, p.149-158, 2020. DOI:

http://doi.org/10.6008/CBPC2179-6858.2020.005.0016 


\section{INTRODUÇÃO}

A ordem Testudines conhecidos atualmente como quelônios, compreendem as tartarugas, jabutis e cágados (ZAHER et al., 2011). Esses animais são ovíparos e depositam seus ovos em diferentes ambientes terrestres, que podem ser praias fluviais ou costeiras (DUPRE et al., 2007). Os Testudines existentes são agrupados em 13 famílias, divididas em duas linhagens os Cryptodira que retraem a cabeça para dentro do casco curvando o pescoço em forma de um $\mathrm{S}$ vertical, e os Pleurodira que retraem a cabeça curvando o pescoço horizontalmente (POUGH, 2003).

São registradas 335 espécies de quelônios no mundo, dentre espécies marinhas e continentais. (BALESTRA, et al., 2016). No Brasil são registradas 36 espécies distribuídas em famílias, sendo duas famílias marinhas, uma família terrestre e cinco famílias dulciaquícolas (SBH, 2007). A família Podocnemidae possui o representante considerado como o maior quelônio de água doce, conhecido popularmente como tartaruga da Amazônia, gênero Podocnemis, espécie $P$. expansa, podendo sua carapaça chegar a medir de 75 a $107 \mathrm{~cm}$ nas maiores extensões de comprimento e 50 a 75 de diâmetro de largura (RODRIGUES, 1992) e pesar $65 \mathrm{Kg}$ (VOGT, 2008).

No Brasil, habita bacias de grandes rios, como Amazonas, Araguaia e Tocantins (VALENZUELA, 2001), possui dieta predominante herbívora, com ciclos de nidificação correlacionados com as relações hídricas do ambiente aquático, podendo ultrapassar 100 ovos por desova (ALMONACID et al., 2007). Sua postura ocorre de setembro a outubro (ALVES JÚNIOR et al., 2013), O período de incubação dos ovos varia entre de 36 a 75 dias (FERREIRA JÚNIOR, 2009) em covas com até $80 \mathrm{~cm}$ de profundidade (LUZ et al., 2005).

Cova de $P$. expansa pode ser identificada pela areia molhada, extraída pelo animal, das partes mais profundas da cavidade, pelo rastro deixado na areia ou, utilizando-se uma varinha que penetra facilmente na cova, sua desova ocorre em locais denominados tabuleiros, caracterizados geralmente por uma pequena porção de areia em uma ilha (ALHO et al., 1982).

Os microrganismos podem colonizar os ovos após a postura, podendo determinar alterações físicas e químicas nos ovos, entre os principais microrganismos que colonizam ovos, estão os fungos e as bactérias (SÁ et al., 2015). Comunidades ribeirinhas tradicionalmente alimentam-se de ovos de quelônios, vale ressaltar que os ovos dos quelônios também são comercializados em algumas comunidades ribeirinhas (BRITO et al. 2016), o consumo de $P$. expansa e seus ovos é uma prática histórica e cultural, desenvolvida pelas comunidades ribeirinhas da região Amazônica (SMITH, 1979). O consumo dos ovos restringe-se ao período de desova, período sazonal (VAILTON et al., 2018).

Dentre as bactérias mais comuns que podem ser encontrados em ovos: destacam-se Salmonella spp., E. coli, Staphylococcus spp., Streptococcus spp., Mycobacterium spp., Campylobacter spp., Mycoplasmas spp, e Chlamydia spp. (FIGUEIREDO, 2008), podendo apresentar características distintas na alteração da qualidade do ovo (SÁ et al., 2015). As infecções por Salmonella spp. em humanos, a partir do contato com répteis tendem a apresentar sintomatologia sistêmica e podem causar quadros severos, podendo levar à morte (HOELZER et al., 2011). 
A contaminação ambiental exerce um papel de importância na transmissão de microrganismos para ovos (SILVA et al., 2002). Os ovos podem ser contaminados por vias vertical e horizontal: na vertical o ovo pode ser contaminado desde a formação (ovário e oviduto). Nesse caso, a contaminação está localizada na gema (SALLES, 2007). Quando o trato intestinal está colonizado, o ovo é contaminado durante a passagem pela cloaca e em poucos minutos o microrganismo é capaz de penetrar através da casca do ovo (CARVALHO, 2005) ou no contato com o ambiente, sendo que existe uma correlação direta entre a contaminação do ambiente e a contaminação dos ovos (SALLES, 2007).

Muitas amostras de microrganismos podem sobreviver por longos períodos de tempo na água e em materiais secos como poeira. Elevado número de microrganismos sobrevive no ambiente, em estado adormecido, podendo multiplicar-se rapidamente se houver condições favoráveis (LIEBANA et al., 2003). Diante do exposto, objetivou-se identificar e traçar o perfil de resistência e ou sensibilidade antimicrobiana de enterobactérias coletadas de ovos $P$. expansa de ambiente natural.

\section{METODOLOGIA}

Os microrganismos foram coletados de 10 ninhos, escolhido aleatoriamente 10 ovos de cada ninho na praia Alta no município da Lagoa da Confusão/TO, na Fazenda Praia Alta, entre as coordenadas geográficas Latitude $10^{\circ} 44^{\prime} 38.3^{\prime \prime}$ S e Longitude 049-51'03.6" W. O ponto das coletas fica em uma praia às margens do rio Formoso, de ambiente lótico, onde há alagamento anual e praias que apresentam apenas na época mais seca, nos meses de junho a setembro. A vegetação do local corresponde basicamente de gramíneas e pequenos arbustos nas áreas alagáveis e uma porção menor de vegetação arbórea nas áreas de terra firme. A coleta de microrganismos dos ovos foi realizada no mês de setembro de 2017, no período matutino. Para identificação dos ninhos foram realizadas caminhadas na praia Alta durante a manhã, à procura de rastros deixados na areia pela fêmea, que facilitavam a localização dos ninhos. Os ovos foram removidos com cuidado, manuseados vagarosamente e depois da coleta dos microrganismos, os ovos foram devolvidos aos ninhos e recoberto com areia de maneira que ficasse como o encontramos. 0 estudo contou com a licença SISBIO n 59466-1.

Coleta e Cultivo do Material Microbiológico: O material microbiológico foi coletado usando Swab estéril friccionando no ovo em toda sua extensão e acondicionados posteriormente, em tubos com meios de cultura de transporte (Meio Stuart). Os tubos, foram transportados ao Laboratório de Microbiologia Médica e Ambiental da Fundação Universidade Federal do Tocantins, Campus de Porto Nacional onde foram realizadas, a cultura, identificação e os testes de susceptibilidade antimicrobiana das enterobactérias coletadas, de acordo com Koneman (2008). Todas as amostras, para o crescimento das colônias foram semeadas em meio ágar MacConkey, por um período de 24 horas, posteriormente as colônias lactose positivas foram semeadas em meio SS (Salmonella-Shigella). A temperatura de incubação foi de $37^{\circ} \mathrm{C}$. Após 24 horas de cultivo, foram realizadas as seleções e caracterização das colônias, levando-se em consideração o tamanho, forma, margem, elevação e coloração. Para o Meio McConkey, foram consideradas as funções de lactose positiva (colônia rosa escuro indica que houve fermentação da lactose) e lactose negativa (colônia 
branca, indicando que não houve fermentação). Depois de selecionadas as UFCs (Unidades formadoras de colônia), cada UFC foi semeada em meio neutro (Agar Muller Hilton) a fim de purificar e isolar a colônia. As colônias repicadas foram cultivadas em placas de petri por mais 24 horas, em estufa a $37^{\circ} \mathrm{C}$ e então identificadas pelos testes bioquímicos (KONEMAN, 2008). As amostras resultantes destas culturas foram submetidas à prova de coloração de gram e as colônias que apresentaram características gram negativas e morfologia em forma de bacilos passaram aos testes de identificação bioquímica para diferenciação e confirmação entre as enterobactérias (KONEMAN, 2008).

Identificação Bioquímica: As colônias com crescimento característicos em MacConkey, ágar Salmonella- Shigella e ágar SIM foram selecionadas e submetidas aos testes de produção de indol, prova do vermelho de metila, prova de voges Proskauer, motilidade, lisina, utilização de citrato, produção de uréase, produção de sulfeto de hidrogênio (KONEMAN, 2008).

Caracterização do Perfil de Sensibilidade à Drogas: As amostras foram isoladas e incubadas em ágar nutriente, a $37^{\circ}$ por 24 horas. Em seguida foram incubadas em placa de petri contendo Ágar Mueller Hinton e incubadas a $37^{\circ}$ por 24 horas (KONEMAN, 2008).

Preparo da Suspensão: Em tubos de ensaio contendo $9 \mathrm{ml}$ de solução de $\mathrm{NaCl} 0.9 \%$, foi inoculada uma alçada de microrganismo, obtendo uma turvação equivalente à escala de 0.5 Mac Farland. Os tubos de ensaio foram bem homogeneizados, após foram transferidos para placa de petri estéril $1 \mathrm{ml}$ da solução de $\mathrm{NaCl}$ a 0,9\% com a suspensão de enterobactérias, em seguida, foram vertidos $25 \mathrm{ml}$ de meio de cultura ágar Mueller Hinton e homogeneizados pela técnica de pouer-plate, padronizadas pelo CLSI (2013).

Teste de Difusão em Disco: A realização deste teste foi baseada nas recomendações do documento M100-S23, tabela 2A, que preconiza as seguintes drogas: amicacina 30 (MCG), imipenema 10 (MCG), cefoxitina 30 (MCG), cotrimoxazol 25 (MCG), gentamicina 10 (MCG), ampicilina 10 (MCG), ceftazidima, 30 (MCG), aztreonan 30 (MCG), cefalotina 30 (MCG). Após adicionado os discos, as placas foram invertidas e incubadas em estufa bacteriológica a $35^{\circ} \mathrm{C}$, por um período de $24-48$ horas. As placas foram analisadas por meio da medida dos halos de inibição, utilizando uma régua milimétrica, sendo as enterobactérias classificadas em sensível, intermediário ou resistente de acordo com os valores de halos obtidos, seguindo tabela de valores do CLSI (2013). As cepas de enterobactérias foram testadas quanto à susceptibilidade aos antimicrobianos empregando-se o método de difusão em disco em ágar Mueller Hinton. A cepa E. coli ATCC 25922 foi utilizada como controle de qualidade dos ensaios.

\section{Análise dos Dados}

Para interpretação dos dados foi aplicada a análise estatística descritiva. A estatística descritiva teve como objetivo básico sintetizar valores de mesma natureza, permitindo obter uma visão global da variação desses valores (VIEIRA, 1980). Foram calculadas as médias de dos halos dos antimicrobianos, e as frequências relativas e absoluta dos microrganismos. 


\section{RESULTADOS E DISCUSSÃO}

Foram identificadas 1.200 colônias de enterobactérias, distribuídas entre os gêneros Enterobacter ssp. Citrobacter spp. Shigella spp. Hafnia ssp. Klebsiella spp. Proteus spp. Salmonella spp. e a espécie E. coli. apresentados na Tabela 1.

Tabela 1: Frequência de ocorrência de enterobactérias coletadas de ovos $P$. expansa de ambiente natural.

\begin{tabular}{|l|l|l|}
\hline \multirow{2}{*}{ Microrganismo } & Frequência & Relativa \\
\cline { 2 - 3 } & Absoluta & $33,33 \%$ \\
\hline Enterobacter spp. & 400 & $12,5 \%$ \\
\hline Shigella spp. & 150 & $8,33 \%$ \\
\hline Hafnia spp. & 100 & $20,83 \%$ \\
\hline E. coli & 250 & $2,08 \%$ \\
\hline Klebsiella spp. & 25 & $1,67 \%$ \\
\hline Proteus spp. & 20 & $0,42 \%$ \\
\hline Salmonella spp. & 05 & $20,83 \%$ \\
\hline Citrobacter spp. & 250 & \\
\hline
\end{tabular}

Todas as amostras de ovos de $P$. expansa oriundas dos 10 ninhos obteve crescimento bacteriano. Foram isolados 08 diferentes gêneros, sendo uma das amostras identificadas em nível de espécie Enterobacter ssp. (33,33\%), Citrobacter spp. (20,83\%), Shigella spp. (12,5\%), E. coli (20,83\%) Hafnia ssp. (8,33\%), Klebsiella spp. (2,08\%), Proteus spp. (1,67\%), Salmonella spp. (0,42\%).

Os gêneros que apresentaram maior frequência foram Enterobacter spp., Citrobacter spp., Shigella spp., e a espécie E. Coli (Fig. 1). Corroborando com Pulcherio et al. (2017) que obtiveram crescimento de bactérias isoladas de ovos de Caiman yacare (Citrobacter freundii, Enterobacter aerogenes, Enterobacter agglomerans, Escherichia coli, Escherichia hermannii, Hafnia alvei, Morganella morganni, Proteus vulgaris, $P$. mirabilis, Salmonella spp., Serratia liquefaciens, S. marcescens e Shigella sonnei), divergindo deste apenas pela ausência de Morganella spp. e Serratia spp. Mayer Júnior (2007) isolou enterobactérias do trato digestório de tartarugas-da-amazônia (Podocnemis expansa) e obteve $(21,22 \%)$ de crescimento para Klebsiella pneumoniae, classificando a como a mais frequente entre as enterobactérias isoladas, diferindo deste estudo, que classifica como mais frequente o Enterobacter spp.

MORAIS et al. (2010), obteve isolamento de Shigella e Klebsiella associado a espécies de tartarugas, esses microrganismos podem ser transmitidos para os ovos por via horizontal e vertical. Pinto et al. (2012) isolaram Enterococcus spp. em areias de duas praias, praia de Gonzaguinha e praia da Ilha Porchat, no Município de São Vicente-SP. Saraiva (2017) realizou uma análise microbiológica da praia de Atalaia em 19 pontos, destes $(68,42 \%)$ foram considerados impróprios para uso, em decorrência da presença de $E$. coli que faz parte do grupo dos coliformes fecais. De acordo com Magalhães et al. (2012) a presença de Escherichia coli em ovos pode ocorrer de maneira endogênica e exogênica, podendo a exogênica está relacionada ao ambiente. Uma vez que bactérias se encontram presentes na casca dos ovos e encontram condições favoráveis, podem penetrar pelos numerosos poros da casca, ultrapassar as membranas e contaminar o conteúdo interno. Segundo Andraus (2006), a temperatura, o potencial de hidrogênio (pH), luz solar, umidade, retenção de água, são elementos importantes que afetam a sobrevivência das bactérias na areia. Panagassi et al. (2011) analisando a microbiologia da areia de praia em Praia Grande/SP, identificaram E. coli, 
Salmonella spp. e enterobactérias em areia molhada e seca. As areias de praias colonizadas com microrganismos podem contaminar os ovos de $P$. expansa por via horizontal, no entanto a contaminação poderá ocorrer também por via vertical no momento da oviposição.

Foram realizados 1.200 antibiogramas de enterobactérias coletadas de ovos $P$. expansa de ambiente natural. A susceptibilidade aos agentes antimicrobianos foi determinada por meio do método de difusão em Ágar segundo as recomendações do CLSI (2013). Os agentes antimicrobianos testados foram: AMI: amicacina 30 (MCG), IPM: imipenema 10 (MCG), CFO: cefoxitina 30 (MCG), SUT: Sulfametoxazol+trimetropim 25 (MCG), GEN: gentamicina 10 (MCG), AMP: ampicilina 10 (MCG), CAZ: ceftazidima, 30 (MCG), ATM: aztreonan 30 (MCG), CFL: cefalotina 30 (MCG)

Tabela 2: Perfil de resistência e sensibilidade de enterobactérias coletadas de ovos $P$. expansa de ambiente natural em Lagoa da Confusão/TO.

\begin{tabular}{|l|l|l|l|l|l|l|l|l|l|}
\hline \multirow{2}{*}{ Microrganismo } & \multicolumn{2}{|l|}{ Sensibilidade $\%$} & ATI & ATM & CFL & IPM \\
\cline { 2 - 10 } & AMP & GEN & SUT & CAZ & CFO & AMI & ATM \\
\hline Enterobacter spp. & $80 \%$ & $100 \%$ & $100 \%$ & $100 \%$ & $96.25 \%$ & $100 \%$ & $100 \%$ & $100 \%$ & $100 \%$ \\
\hline Shigella spp. & $83.24 \%$ & $100 \%$ & $94.67 \%$ & $90 \%$ & $100 \%$ & $100 \%$ & $98.67 \%$ & $95.34 \%$ & $100 \%$ \\
\hline Hafnia spp. & $85 \%$ & $100 \%$ & $93 \%$ & $100 \%$ & $92 \%$ & $100 \%$ & $100 \%$ & $100 \%$ & $92 \%$ \\
\hline E. coli & $80 \%$ & $94 \%$ & $100 \%$ & $95.2 \%$ & $91.2 \%$ & $94 \%$ & $100 \%$ & $100 \%$ & $98.8 \%$ \\
\hline Klebsiella spp. & $80 \%$ & $100 \%$ & $100 \%$ & $100 \%$ & $72 \%$ & $100 \%$ & $100 \%$ & $100 \%$ & $100 \%$ \\
\hline Proteus spp. & $90 \%$ & $85 \%$ & $100 \%$ & $100 \%$ & $95 \%$ & $100 \%$ & $100 \%$ & $100 \%$ & $100 \%$ \\
\hline Salmonella spp. & $80 \%$ & $100 \%$ & $100 \%$ & $100 \%$ & $100 \%$ & $100 \%$ & $100 \%$ & $100 \%$ & $100 \%$ \\
\hline Citrobacter spp. & $92 \%$ & $95.2 \%$ & $100 \%$ & $100 \%$ & $90 \%$ & $96.4 \%$ & $100 \%$ & $100 \%$ & $100 \%$ \\
\hline
\end{tabular}

De acordo com a figura 2, E. coli, Shigella spp., Hafnia spp. e Citrobacter spp. representam os microrganismos coletados mais difíceis de serem eliminadas com antibioticoterapia, apresentando multirresistência aos antimicrobianos em mais de 04 dos antibióticos utilizados, frente aos microrganismos de ovos de $P$. expansa de ambiente natural. De acordo com Mesquita et al. (2009) cepas patogênicas multirresistentes aos antimicrobianos ocorrem em larga distribuição geográfica. Um estudo realizado por Bastos et al. (2010), apresentou resistência a todos os antimicrobianos testados. Silva Sobrinho et al. (2016) identificaram em seu estudo que (80\%) dos isolados de Shigella spp. apresentaram resistência à imipenem, cefalotina e ampicilina, diferindo deste trabalho quanto ao imipenem e cefalotina que apresentaram sensibilidade em (100\%) das amostras testadas. Erazo-Carlos et al. (2016) obtiveram (100\%) de sensibilidade à gentamicina corroborando com este estudo.

E. coli, é uma bactéria com vários sorotipos encontrada no intestino de várias espécies animais, podendo desencadear no hospedeiro animal afecções gastrointestinais (PHILLIPS et al. 2004), Nos testes de susceptibilidade das cepas de $E$. coli isoladas de ovos $P$. expansa frente aos antimicrobianos utilizados na prática clínica, verificou-se bom perfil sensibilidade para 08 dos antibióticos testados, com (100\%) de sensibilidade para sulfametoxazol+trimetoprim, cefalotina e aztreonam, e sensibilidade reduzida em ampicilina (80\%). Santana et al. (2012), encontrou (52\%) de resistência à ampicilina, (41\%) à cefalotina, e (46\%) sulfametatoxazol+trimetropim, em um estudo sobre a prevalência de resistência bacteriana aos agentes antimicrobianos de primeira escolha em infecções do trato urinário, divergindo deste quanto aos antimicrobianos sulfametatoxazol+trimetropim e cefalotina. Cunha (2014) estudando E. coli de peru com doença respiratória obteve resistência de (5.7\%) para cefoxitina e (19.5\%) para gentamicina. 
Nos testes de susceptibilidade das cepas de Klebsiella spp. isoladas de ovos $P$. expansa de frente aos antimicrobianos, verificou-se que $(77,78 \%)$ apresentaram $100 \%$ de sensibilidade, com sensibilidade diminuída em ampicilina (80\%) e cefoxitina (72\%). Silveira et al. (2014) identificaram resistência à gentamicina, ampicilina e sulfametatoxazol+trimetropim em Klebsiella spp. isoladas de Chelonoidis carbonaria (jabuti). Nos testes de susceptibilidade frente a Proteus spp, verificou-se bom perfil sensibilidade para $(66,77 \%)$ dos antimicrobianos testados, apresentando sensibilidade reduzida em gentamicina, ampicilina e cefoxitina. Porém, Braoio et al. (2009) encontraram à ampicilina em $(57,9 \%)$ e sulfametoxazol+trimetoprim $(53,6 \%)$.

Nos testes de susceptibilidade frente a Salmonella spp. verificou-se excelente perfil sensibilidade para os antibióticos testados, exceto para ampicilina que apresentou (20\%) de resistência. PINHEIRO et al. (2010) analisaram 37 cepas de Salmonella spp. isoladas de granjas avícolas na cidade de Uberlândia-MG e obtiveram bons resultados de sensibilidade (100\%) para gentamicina, ampicilina (97,3\%), imipenema $(91,9 \%)$, ceftazidima $(91,9 \%)$ e resistência de $(43,34 \%)$ para amicacina. Sá et al. (2015) traçou o perfil antimicrobiano de Salmonella spp., isolada de casca de ovo caipira e identificou resistência à ampicilina em (25\%) das amostras que as amostras, resultado próximo ao encontrado neste estudo, detectado (20\%) de resistência à ampicilina.

Nos testes de susceptibilidade frente a Citrobacter spp. verificou-se que 05 dos antibióticos testados não apresentaram resistência e 04 dos antimicrobianos apresentaram sensibilidade reduzida, com (96,4\%) de sensibilidade amicacina, (95,2\%) gentamicina, (92\%) ampicilina e (90\%) cefoxitina. Nos testes de susceptibilidade frente a Enterobacter spp. verificou-se apresentar bons padrões de sensibilidade apresentando resistência apenas em cefoxitina $(96,25 \%)$ e ampicilina com (80\%) de sensibilidade.

Para Barancelli et al. (2012) O ovo é um dos alimentos mais nutritivos da natureza, fonte de proteínas de alto valor biológico e de baixo custo, no entanto, dados epidemiológicos demonstram sua importância como veículo de Salmonela para a população em todo o mundo, em decorrência disso não deverá ser consumido antes da cocção, processo pelo qual possibilita a destruição do microrganismo, com cozimento adequado em que a temperatura no centro geométrico do ovo deve atingir 74 으. Ovos só devem ser consumidos após que cocção tenha atingindo 74 @C no interior (SÃO PAULO, 2008). Todavia nos locais em que há o consumo in natura de ovos poderá propiciar doenças gastrointestinais como a Salmonelose humana, doença comum, sendo uma das maiores preocupações da saúde pública, pois mesmo em países bem desenvolvidos, gera-se um custo significante para a sociedade (SHINOHARA, 2008).

Portanto é possível destacar que as enterobactérias isoladas de ovos de $P$. expansa de ambiente natural, possuí diferentes níveis de susceptibilidade frente aos antimicrobianos utilizados na prática clínica, demonstrando a importância de se conhecer a eficácia de cada antibiótico frente aos microrganismos, possibilitando assim acompanhar a evolução dos microrganismos e a busca de novas alternativas terapêuticas. 


\section{CONCLUSÕES}

Os resultados obtidos neste estudo ressaltam a importância de se conhecer o perfil de enterobactérias isoladas de ovos de $P$. expansa, tendo em vista que tais bactérias são encontradas como integrantes da microbiota residente e transitória da espécie e da areia das praias. Sobretudo por os ovos fazerem parte da dieta de ribeirinhas da região amazônica e pelas características que as enterobactérias têm, de desencadear afeç̧ões em humanos e animais, podendo até afetar os embriões dentro dos ovos, além disso, pela habilidade de desenvolverem resistência aos antimicrobianos utilizados na prática clínica humana e veterinária, que pode ser acelerada pelo uso indiscriminado de tais antibióticos.

E. coli, Shigella spp., Hafnia spp., e Citrobacter spp. coletadas de ovos de P. expansa de ambiente natural foram os microrganismos que apresentaram resistência ao maior número de antimicrobianos utilizados na prática clínica. Todas as bactérias analisadas apresentaram resistência a uma ou mais classes de antimicrobianos. Enterobacter spp, E. coli e Citrobacter spp. foram as enterobactérias encontradas em maior número de ovos, podendo estar relacionadas com a microbiota da areia da praia, contaminando os ovos por via horizontal.

\section{REFERÊNCIAS}

ALHO, C. J. R.; PADUA, L. F. M.. Reproductive parameters and nesting behaviour of Amazon turtle Podocnemis expansa (Testudinata: Pelomedusidae) in Brazil. Canadian Journal of Zoology, Ottawa, v.60, n.2, p.97-103, 1982. DOI: https://doi.org/10.1139/z82-012

ALMONACID, J. V.; CARR, J. L.; MITTERMEIER, R. A.; RODRÍGUEZMAHECHA, J. V.; MAST, R. B.; VOGT, R. C.; MITTERMEIER, C. G.. Las tortugas y lós crocodrilianos de lós Países Andinos del Trópico. Conservação Internacional. Bogotá: Panamericana, Formas e Impresos., 2007.

ALVES JÚNIOR, J. R. F.. Leptospira spp. e Brucella spp.em tartarugas da Amazônia (Podocnemis expansa) do Vale do rio Araguaia/GO. Jaboticabal. Tese (Doutorado) Universidade Estadual Paulista Júlio Mesquita Filho, Jabototicabau, 2013.

ANDRAUS, S.. Aspectos microbiológicos da qualidade sanitária das águas do mar e areias das praias de matinhos, Caiobá e Guaratuba/PR. Dissertação (Mestrado) Universidade Federal do Paraná, Curitiba, 2006.

BALESTRA, R. A. M.; VALADÃO, R. M. V.; VOGT, R. C.; BERNHARD, R.; FERREIRA, C. R.; BRITO, E. S.; ARIAS, R. B.; MALVÁSIO, A.; LUSTOSA, A. P. G.; SOUZA, F. L.; DRUMMONDS, G. M.; BASSETTI, L. A. B; COUTINHO, M. E.; JÚNIOR, P. D. F.; CAMPOS, Z. M. S.; MENDONÇA, S. H. S.; ROCHA, J. M. N.; LUZ, V. L. F.. Roteiro para inventários e monitoramentos de quelônios continentais. Biodiversidade Brasileira, v.6, n.1, p.114-152, 2016.

BASTOS, F. C.; LOUREIRO, E. C.. Caracterização da resistência antimicrobiana de amostras de Shigella spp. isoladas em Belém, Estado do Pará, Brasil (1990-2000). Revista PanAmazônica de Saúde, Belém, v.1, n.4, p.71-74, 2010. DOI: htpps://dx.doi.org/10.5123/S2176-62232010000400011
BRAOIOS, A.; TURATTI, T. F.; MEREDIJA, L. C.; CAMPOS, T. R. S.; DENADAI, F. H. M.. Infecções do trato urinário em pacientes não hospitalizados: etiologia e padrão de resistência aos antimicrobianos. Jornal Brasileiro de Patologia e Medicina Laboratorial, Rio de Janeiro, v.45, n.6, p.449-456, 2009.

BARANCELLI, V. B.; MARTINS, J. G. P.; PORTO, E.. Salmonella em ovos: relação entre produção e consumo seguro. Segurança Alimentar e Nutricional, Campinas, v.19, n.2, p.73-82, 2012 DOI: https://doi.org/10.20396/san.v19i2.8634612

BRITO, T. P.; LIMA, E. B. S.; ROSA, J. C. G. S.. Avaliação do consumo de quelônios no município de Castanhal/PA. Revista Ouricuri, Paulo Afonso, Bahia, v.6, n.1, p.071-103, 2016.

CARVALHO, J. C. A. P.. Avaliação de parâmetros da pasteurização de ovos em casca, considerando a destruição de Salmonella enterides. Tese (Doutorado) - Universidade Federal Fluminense, Niterói, 2005.

CLINICAL AND LABORATORY STANDARDS INSTITUTE. Performance standards for antimicrobial disk susceptibility tests, Wayne, v. 33, n. 1, M-100 S-23, 2013.

CUNHA, M. P. V.. Resistência aos antimicrobianos e virulência de Escherichia coli patogênica para aves (APEC) isoladas de perus com doença respiratória. Dissertação (Mestrado) - Universidade de São Paulo, São Paulo, 2014.

DUPRE, A.; DEVAUX, B.; BONIN, F.. Turtles of the World. A \& C Black. London, 2007.

ERAZO-CARLOS, PRADO-REYES, Y. N. D.; GONZALES-ORE, V. H.; CAPUÑAY-BECERRA, Y. C. Enterobacterias y su resistência antimicrobiana em el caimán blanco (Caiman crocodilus) de 
vida libre en el río Madre de Dios, Tambotá - Peru. Revista Latinoamericana de Recusos Naturales, Ciudad Obregó, v.12, n.2, p. 53-59, 2016.

FERREIRA JÚNIOR, P. D.. Aspectos ecológicos da determinação sexual em tartarugas. Acta Amazônica, v.39, n.1, p.139-154, 2009. DOI: http://dx.doi.org/10.1590/S0044$\underline{59672009000100014}$

FIGUEIREDO, T. C.. Características físico-química e microbiológica e aminas bioativas em ovos de consumo. Dissertação (Mestrado) - Universidade Federal de Minas Gerais, Belo Horizonte, 2008.

HOELZER, K.; SWITT, A. I. M.; WIEDMANN, M.. Animal contact as a source of human non-typhoidal salmonellosis. Veterinary Research, Londres, v. 42, n. 1, p. 34, 2011. DOI: https://doi.org/10.1186/1297-9716-42-34

KONEMAN, E. W.; ALLE, N. S. D.; JANDA, W. M.; SCHRECKENBERGER, P. C.; WINN, W. C.. Diagnóstico microbiológico: texto e atlas colorido. 6 ed. Rio de Janeiro: Guanabara Koogan, 2008.

LIEBANA, E.; GARCIA-MIGURA, L.; CLOUTING, C.; CLIFTONHADLEY, F. A.; BRESLIN, M.; DAVIES, R. H.. Molecular fingerprinting evidence of the contribution of 119 wildlife vectors in the maintenance of Salmonella Enteritidis infection in layer farms. Journal of Applied Microbiology. v.94, p.1024-1029, 2003. DOI:

https://doi.org/10.1046/j.1365-2672.2003.01924.x

LUZ, V. L. F.; REIS, I. J.. Criação comercial de tartaruga e tracajá. Manual técnico. Cuiabá: SEBRAE, 2005.

MAGALHÃES, A. P. C.; CURVELLO, F. A.; MORENZ, M. J.; CALIXTO, L. F.; REZENDE, S. R. F.. Qualidade de ovos comerciais de acordo com a integridade da casca, tipo de embalagem e tempo de armazenamento. Revista de Ciência da Vida, v.32, p.51-62, 2012.

MAYER NÚNIOR, J. C.. Determinação qualitativa de enterobactérias presentes em tartarugas da Amazônia (Podocnemis expansa) de vida livre e cativeiro. Dissertação (Mestrado) - Universidade Federal do Pará, Belém, 2007.

MESQUIRA, A. M. C.; LIMA, N. L.; LIMA, A. Â. M.. Avaliação da susceptibilidade e resistência antimicrobiana de cepas de Shigella spp. isoladas de pacientes com diarreia nosocomial. Revista de Ciências médicas e biológicas, Salvador, v.8, n.3, p.292-300, 2009.

DOI: http://dx.doi.org/10.9771/cmbio.v8i3.4469

MORAIS, P.B.; OLIVEIRA, K.W.; MALVASIO, A; ATAÍDES, A. G.; PIMENTA, R. S.. Enterobacteriaceae associated with eggs of Podocnemis expansa and Podocnemis unifilis (Testudines: Chelonia) in nonpolluted sites of a National Park 21 of Araguaia Plains, Brazil. Journal of Zoo and Wildlife Medicinev, Washington, v.41, n.4, p.656- 661, 2010. DOI: https://doi.org/10.1638/2010-0027.1

PANAGASSI, K. A. L.; CATANOZI, G.. Caracterização bacteriológica da areia de praia do município estância balneária de praia grande/SP. Rev. Ibirapuera, São Paulo, n.2, p.28-32, 2011.

PINTO, A. B.; PEREIRA, C. R.; OLIVEIRA, A. J. F. C.. Densidade de Enterococcus sp em águas recreacionais e areias de praias do município de São Vicente-SP, Brasil e sua relação com parâmetros abióticos. O Mundo da Saúde, São Paulo v.36, n.4, p.587-593, 2012. DOI: $10.15343 / 0104-$ 7809.2012364587593

PINHEIRO, L.; MELO, R. T.; MENDONÇA, E. P.; COELHO, L. R.; MONTEIRO, G. P.; ROSSI, D. A.. Perfil de suscetibilidade antimicrobiana de cepas de Salmonella spp. isoladas de granjas avícolas. PUBVET, Londrina, v.4, n.34, 2010.

PHILLIPS, I.; CASEWELL, M.; COX, T.; DE GROOT, B.; FRIIS, C.; JONES, R.; NIGHTINGALE, C.; PRESTON, R.; WADDELL, J.. Does the use of antibiotics in food animals pose a risk to human health? Journal of Antimicrobial Chemotherapy, London, v.53, n.1, p.28-52, 2004. DOI: https://doi.org/10.1093/jac/dkg483

POUGH, F. H.; JANIS, C. M.; HEISER, J. B.. A Vida dos Vertebrados. 3 ed. São Paulo: Atheneu, 2003.

PULCHERIO, R.; MARUYAMA, F.H.; RORADO-RODRIGUES, T.; SILVEIRA, M.; DUTRA, V.; FERRAZ, R.. Microbiota bacteriana de ovos de jacaré-do-pantanal incubados naturalmente. Arq. Bras. Med. Vet. Zootec., v.69, n.6, p.1676-1682, 2017. DOI: htpp://dx.doi.org/10.1590/1678-4162-9575

RODRIGUES, R. M.. Quelônios. In: A fauna da Amazônia. Belém: CEJUP, 1992. p.209-214.

SÁ, J. L. S. E.; SANTANA, E. S.; ALMEIDA, T. F.; ALMEIDA, I. F.; ALCÂNTARA, N. R.. Avaliação bacteriológica de ovos comercializados no município de Palmeiras de Goiás. Enciclopédia biosfera: Centro científico conhecer, Goiânia, v.11, n.55, p.2871-2881, 2015 DOI: http://dx.doi.org/10.18677/Enciclopedia Biosfera 201500 7

SALLES, R. P. R.. Pesquisa de Salmonella spp. em galinhas poedeiras e enterobactérias em ovos comerciais da região metropolitana de Fortaleza. Tese (Doutorado) Universidade Estadual do Ceará, Fortaleza, 2007.

SANTANA, T. C. F. S.; MAIÃO, R. C.; MONTEIRO, S. G.; CARMO, M. S.; FIGUEIREDO, P. M. S.. Perfil de resistência de Escherichia coli e Klebsiella spp. Isoladas de Urocultura de Comunidade do Município de São Luís/MA. Revista de Patologia Tropical/Journal of Tropical Patology, São Luís, v.41, n.3, p.295-303, 2012.

DOI: https://doi.org/10.5216/rpt.v41i3.20754

SÃO PAULO. Secretaria de Estado da Saúde. Portaria do Centro de Vigilância Sanitária n. 18, de 09 de setembro de 2008. Regulamento técnico sobre os parâmetros e critérios para o controle higiênico-sanitário em estabelecimentos de alimentos. São Paulo, 2008.

SARAIVA, H. L.. Avaliação do risco microbiológico nas areias da praia do Atalaia, Salinópolis-PA. Monografia

(Bacharelado) - Universidade Federal Rural da Amazônia, Copanema, 2017.

SILVEIRA, M. M.; MORGADO, T. O.; LOPES, E. R.; KEMPE, G. V.; CORREA, S. H. R.; GODOY, I.; NAKAZATO, L.; DUTRA, V.. Pneumonia bacteriana em jabuti-piranga (Chelonoidis carbonaria): aspectos clínicos, microbiológicos, radiológicos e terapêutica. Pesquisa Veterinária Brasileira, Rio de 
Janeiro, v.34, n.9, p.891-895, 2014. DOI: https://doi.org/10.1590/S0100-736X2014000900014

SBH. Sociedade Brasileira de Herpetologia. Lista de espécies de répteis do Brasil. SBH, 2007.

SHINOHARA, N. K. S.; BARROS, V. B.; JIMENEZ, S. M. C.; MACHADO, E. C. L.; DUTRA, R. A. F.; FILHO, J. L. L.. Samonella spp., importante agente patógeno veiculado em alimentos. Revista Ciências \& Saúde Coletiva, v.13, n.5, p.1675-1683, 2008. DOI: https://doi.org/10.1590/S141381232008000500031

SMITH, N. J. H.. Aquatic Turtle of amazonia: An endangered resource. Biological Conservation, v.16, n.3, p.165-176, 1979. DOI: https://doi.org/10.1016/0006-3207(79)90019-3

SILVA SOBRINHO, F. B. S.; SÁ, M. C.; GOUVEIA, G.V.; COSTA, M. M.; FARIA, M. D., MILANELO, L.; GRADELA, A.. Isolamento e determinação de sensibilidade e resistência a

antimicrobianos de cepas bacterianas presentes na cloaca de Trachemys scripta elegans (Wied, 1839) criadas em cativeiro em Petrolina, PE. Pesquisa Veterinária Brasileira, Rio de Janeiro, v.37, n.3, p.261-268, 2017. DOI: https://dx.doi.org/10.1590/s0100-736x2017000300010
SILVA, E.N.; DUARTE, A.. Salmonella enteritidis em aves: Retrospectiva no Brasil. Revista Brasileira de Ciência Avícola, Campinas, v.4, n.2, p.85-100, 2002. DOI: https://doi.org/10.1590/s1516-635×2002000200001

VAILTON, A.; MALVÁSIO, A.. Aspectos sobre a caça, comercialização e consumo de quelônios na região do corredor ecológico Araguaia Bananal no Estado do Tocantins. Revista Ouricuri, Juazeiro, v.8, n.2, p.080-103, 2018.

VALENZUELA, N.. Maternal effects on life-history traits in the Amazonian gian river turtle Podocnemis expansa. Journal of Herpetology, Athens, v.35 n.3, p.368-378, 2001. DOI: https://doi.org/10.2307/1565954

VIEIRA, S.. Introdução à bioestatística. 3 ed. Rio de Janeiro: Elsevier, 1980.

VOGT, R. C.. Tartarugas da Amazônia. Brasília: INPA, 2008.

ZAHER, H.; BARBO, F. E.; MARTINEZ, P. S.; NOGUEIRA, M. T.; RODRIGUES, SAWAIA, R. J.. Répteis do estado de São Paulo: Conhecimento atual e perspectivas, Biota Neotropica, Campinas, v.11, n.1, p.67-81, 2011

A CBPC - Companhia Brasileira de Produção Científica (CNPJ: 11.221.422/0001-03) detém os direitos materiais desta publicação. Os direitos referem-se à publicação do trabalho em qualquer parte do mundo, incluindo os direitos às renovações, expansões e disseminações da contribuição, bem como outros direitos subsidiários. Todos os trabalhos publicados eletronicamente poderão posteriormente ser publicados em coletâneas impressas sob coordenação da Sustenere Publishing, da Companhia Brasileira de Produção Científica e seus parceiros autorizados. Os (as) autores (as) preservam os direitos autorais, mas não têm permissão para a publicação da contribuição em outro meio, impresso ou digital, em português ou em tradução. 